\title{
THE MOREL FUNGUS IN SOUTHERN SASKATCHEWAN
}

\author{
H.E. MANN, Biology Department, Sir Wilfred Grenfell College, Memorial \\ University of Newfoundland, Corner Brook, NF. A2H 6P9 and M.V.S. RAJU, \\ Department of Biology, University of Regina, Regina, SK. S4S 0A2
}

It is seldom that reports or photographs of fungi appear in the Blue Jay and yet this is a subject that can become a fascinating study. ${ }^{7}$ Indeed, it is fascinating to have some knowledge of the fungi which is perhaps one of the most important groups involved in the process of biological recycling. Unfortunately, in these times of fast progressing modern biotechnology, very few individuals are interested in the biology and field identification of fungi. Furthermore, the science of mycology (study of fungi) itself is a very neglected field in the undergraduate curriculum of most universities.

The morels are often, for the purpose of convenience, recognized as mushrooms. ${ }^{2,5}$ True mushrooms belong to a group known as Basidiomycotina, whose fruiting bodies are called basidiocarps which produce basidia and basidiospores. In contrast, the morels belong to a completely different group known as Ascomycotina, whose fruiting bodies are the ascocarps that produce asci and ascospores. Some references are provided in the literature cited which give a good overview of the general morphology and reproduction of mushrooms, morels and other fungi.

True morels (Morchella species) are found all over the world, but their abundance is especially obvious in the temperate regions of the northern hemisphere. They are all basically saprophytic (depend on organic debris for growth and development) and the fruiting bodies occur singly or in clusters in a variety of habitats. Pratt $^{7}$ has reported their occurrence in the northern woodlands of Saskatchewan where abundant organic debris and moisture are available. In southern Saskatchewan they are most commonly found associated with the poplar-spruce-pine tree woods where an abundant ground cover of litter is present. They also occur in exposed areas in sandy soil as long as there is ample moisture and humus (Fig. $1 \mathrm{a}, \mathrm{b}$ ). Abundant occurrence of morels in the prairies is seen early in spring (April to May) in aspen woodlands and in open prairies. However, their occurrence in the open prairies is rare and less abundant. Occasionally, they may appear in places where snow is melting early in spring around aspen woodlands in the Strawberry Lakes area. They may also occur sporadically in summer after rain in woods and in areas rich in organic debris, on the open prairies of southern Saskatchewan.

The morels can be identified easily by their characteristic mature reproductive structure called the fruiting body or, more technically, the ascocarp. The fruiting body consists of 

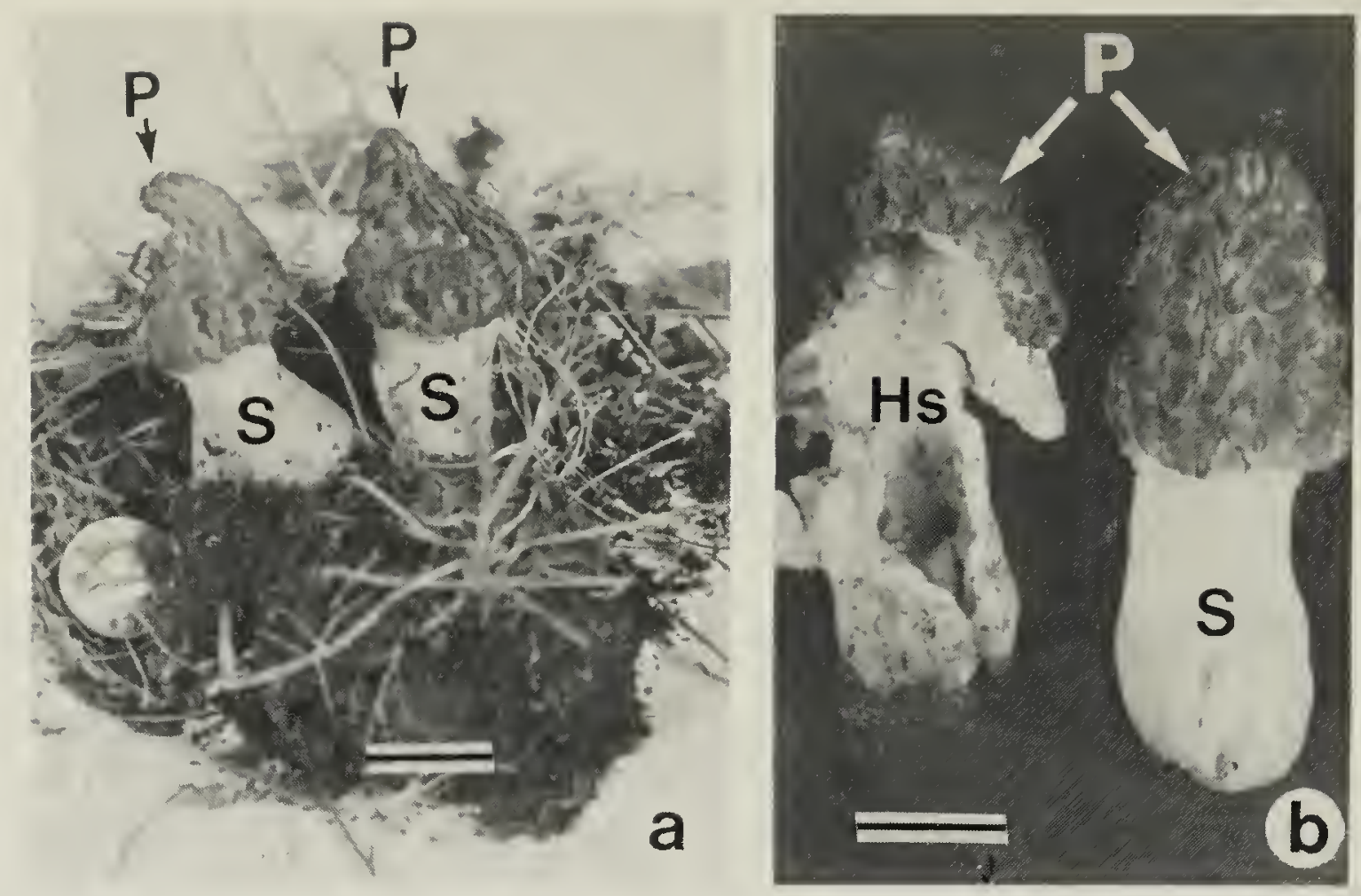

Figure 1a. Morchella esculenta in a grassland area in the Cypress Hills of southern Saskatchewan. Bar $=2.0 \mathrm{~cm}$.

Figure 1b. Morchella esculenta growing in poplar woods near Strawberry Lakes. Note the hollow stipe in one. Bar $=2.0 \mathrm{~cm}$.

(Abbreviations in figures: $\mathbf{A}$, ascus; As, ascospores; $\mathbf{H}$, hymenium or fertile layer containing hyphae, asci and paraphyses; Hs, hollow stipe or stalk; $\mathbf{P}$, pileus or cap; $\mathbf{P a}$, paraphyses or hairs; $\mathbf{P i}$, pits or depressions; $\mathbf{R}$, ridges or elevated borders of pits; $\mathbf{S}$, stipe or stalk).

two parts, the yellowish or brownish pileus (cap) and the supporting whitish long to short stalk or stipe (Figs. $1 \mathrm{a}, \mathrm{b} ; 2 \mathrm{a})$. The shape of the entire reproductive structure with its pileus and stalk varies considerably, with the general construction or structure of it being about the same in all. In most instances the pileus appears as a conical structure with a distal pointed or blunt top. The stalk or stipe that bears the pileus at its distal end may vary in thickness and length. Ordinarily, the pileus, throughout its length, is internally fused with the stalk (Fig. 2 b). The stipe, short or long, remains hollow (Fig. 2 b). In some morels only about a third of the distal part or sometimes much less, of the pileus, is intimately associated or fused with the stalk and the rest of it is free from it (Fig. $2 \mathrm{i}, \mathrm{j}$ ).

Externally the pileus shows char- acteristic ridges and furrows or pits (Figs. 1 a, b; 2 a). The ridges are usually irregular and consequently the pits also appear irregular. In some cases the pits are large and may elongate longitudinally, a feature which is important in the identification of morels (Fig. 2 d-h). The ridges may vary in colour from yellowish white to dark brown. The pits are usually darker than the ridges. Thin sections of the cap with pits, when examined in the microscope, show characteristic invaginations (Fig. $2 \mathrm{k}, \mathrm{l}$ ). The inner surface of the invagination is lined with a differentiated region called the hymenium or the fertile layer (Fig. $2 k, 1$ ). The hymenium is made up of densely packed filamentous mycelia from which develop two modified cell types. The first cell type is the elongated club-shaped sac or ascus (asci, plural), enclosing the spores, 


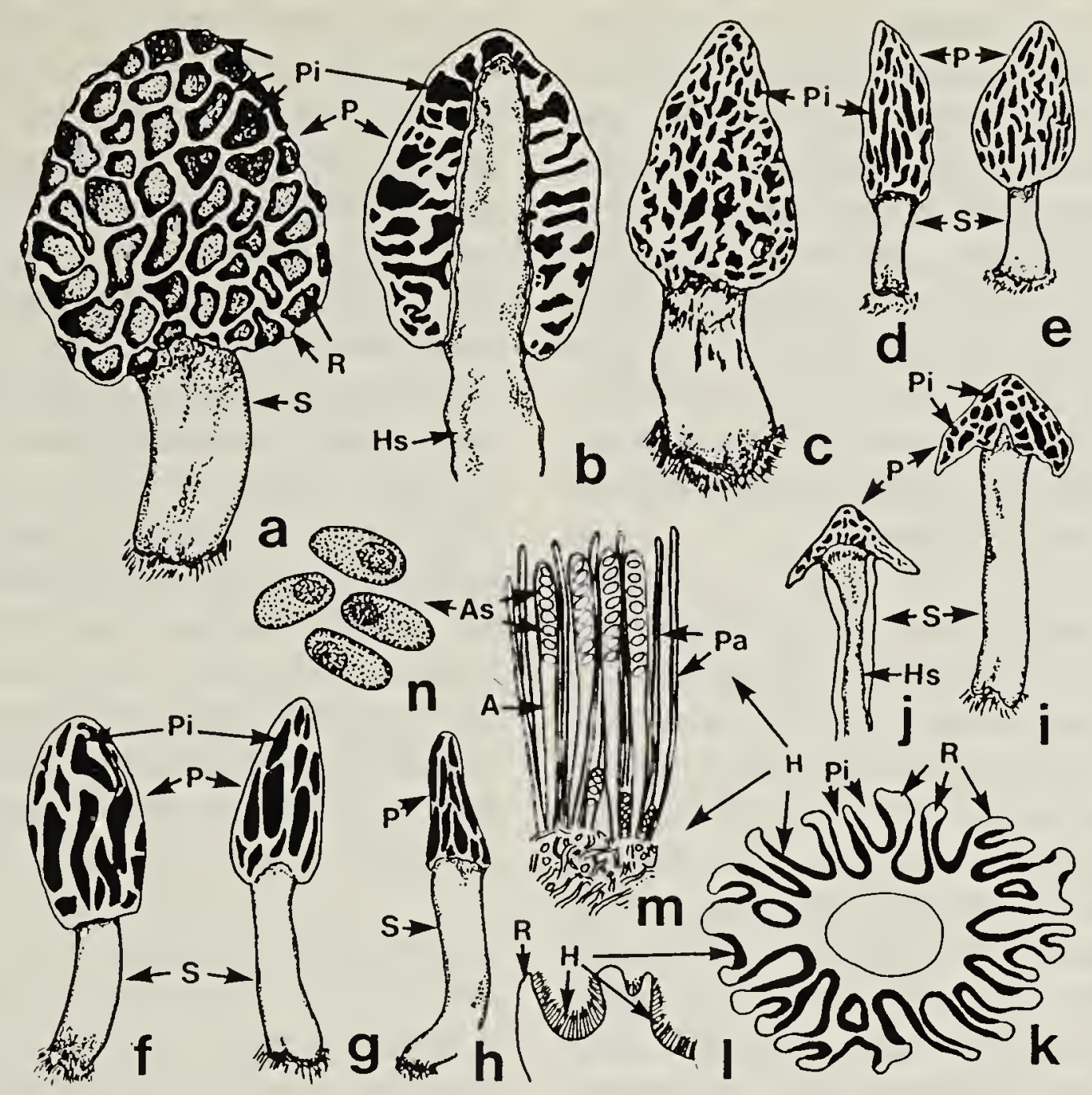

Figure 2a. Diagram of M. esculenta collected from poplar-pine woods, showing pileus (cap), stalk, pits and ridges in the cap. $\times 1 / 2$.

Figure $2 b . \mathrm{M}$. esculenta long section of the fruiting body to show the hollow stipe and the attachment of cap to the stalk. $\times 1 / 2$.

Figure 2c. M. esculenta collected from open grassland (sandy soil with organic debris) in the Cypress Hills. The pileus is somewhat conical with a blunt tip. $\times 1 / 2$.

Figure 2d,e. M. deliciosa, collected from poplar woods in the Cypress Hills. Note somewhat vertically elongated pits. $\times 1 / 3$.

Figure 2f-h. M. elata, collected in the fall from poplar-pine logged woods in the Cypress Hills. They were growing between dead logs on thick humus and sandy soil. Note the elongated pits in the cap. It is morphologically a highly variable species. $x$ 1/2. Figure 2i,j. M. semilibera, collected from disturbed areas of a tree-logged habitat in the Cypress Hills. Note the short cap and a hollow stipe in long section in j. Only a small upper part of the cap is fused with the stalk. Note the flared out margins of the cap. $\times 1 / 2$.

Figure $2 k . M$. esculenta, Diagrammatic cross section of the cap to show the central hollow stipe surrounded by irregular depressions or pits and ridges. The dark region in the invaginations is the hymenium. $\times 1$.

Figure 21. M. esculenta, diagram of a part of the cap enlarged to show the ridges and pits. The slashed area in the pits between ridges is the hymenium or the fertile layer. $x 100$.

Figure $2 m$. M. esculenta, enlarged diagram of the hymenium showing asci with ascospores and the sterile elongated unicellular hairs or paraphyses. In each mature ascus there are 8 ascospores developed. $\times 400$.

Figure $2 n$. M. esculenta, highly enlarged diagram of oval white ascospores. $x 600$. 
which are called the ascospores (Fig. $2 \mathrm{~m}$ ). The second cell type includes a large thin elongated tubular cell called the paraphyses (paraphysis, singular), developed from the mycelia, which lie between the asci and they do not contain spores (Fig. $2 \mathrm{~m}$ ). The asci, by an interesting and complicated mechanism dealing with turgidity in relation to the environmental conditions, expel the oval ascospores, the basic asexual reproductive units (Fig. 2 n).

The ascospores, under favourable growth conditions, can germinate and produce dense masses of filamentous mycelia which usually remain below the soil, occasionally associated with roots of other plants. Eventually, they produce the fruiting bodies or ascocarps. Alternatively they may remain dormant or overwinter and germinate in the following spring to produce large tangles of mycelia from which emerge the ascocarps or the fruiting bodies. More details of these morels can be found in some books on fungi. ${ }^{1,4}$

Studies were conducted on morels found in the eastern part of the Cypress Hills and in the Strawberry Lakes area in southern Saskatchewan. Many morphologically variable forms of morels, all belonging to the genus Morchella, were examined. In accordance with the morphological details provided by Arora, ${ }^{2}$ they were relegated to four identifiable species. Some salient morphological details of the four species are given below.

Morchella esculenta (Common or Yellow Morel: Figs. 1 a, b; 2 a-c). The cap of the fruiting body may vary from round to oval, distally conical, blunt or irregular. It is quite variable in length or height $(25-74 \mathrm{~mm})$ and width $(15-64 \mathrm{~mm})$. The shape of pits may vary from irregular (not ar- ranged in well-defined rows) to regular. Pits are small or sometimes large. Colour of pits may range from yellowish to brown or tan. Ridges around pits are normally narrow. The margin of the cap is fused with the stalk. The stalk is thick $(20-40 \mathrm{~mm})$ and long or high $(22-55 \mathrm{~mm})$, and it is hollow (Figs. $1 \mathrm{~b} ; 2 \mathrm{~b}$ ); its colour may vary from white to buff. The adult form occurs singly or in groups of two to four individuals, relatively more abundant than other species except $M$. deliciosa. The species can be seen in the leaf litter of pine and spruce forests from April to June in the Cypress Hills and in the aspen woods near Strawberry Lakes. It seems to prefer moist sandy soil along the edges of woods.

Morchella deliciosa (White Morel: Fig. $2 \mathrm{~d}$, e). Cap of the fruiting body is round to oval or conical. Colour of the cap may be dark gray, dark brown, grayish tan or brown (colour may also change with age, usually darker when young and paler after). Its margin is attached to the stalk. The cap is $40-50 \mathrm{~mm}$ long or high and $20-28 \mathrm{~mm}$ thick or wide. The large pits are somewhat vertically elongated, not always arranged in rows. Pits and ridges show about the same colour. The stalk may be thicker (never thicker than the cap) below and thinner above. The stalk is $8-24 \mathrm{~mm}$ long and $8-22 \mathrm{~mm}$ wide, and it is hollow. This species occurs in the Cypress Hills and also in the Strawberry Lakes area. It seems to prefer sandy soil with considerable moisture and organic matter. In the pine-spruce-aspen woods, it occurs singly or in small clusters (2-3), especially in leaf litter from late April to early June. When abundant moisture is present in the soil and litter, this species seems to be most common.

Morchella elata (Black Morel: Fig. 2 
$f-h)$. The cap is conical, oval, narrow or somewhat irregular in shape. Colour of the cap may vary, usually the old fruiting bodies are dark brown. The margin of the cap is attached to the stalk. The cap is $20-50 \mathrm{~mm}$ long and $10-35 \mathrm{~mm}$ wide. The pits are vertically elongated (placed somewhat in longitudinal rows), and their colour is yellow-brown to dark-brown or rarely reddish brown. The stalk is hollow. It is $20-40 \mathrm{~mm}$ long and $10-$ $20 \mathrm{~mm}$ wide. This species occurs in spruce-pine-poplar woods in the Cypress Hills and along their moist edges. It is rather rare in the Strawberry Lakes area. Occasionally, it is found singly or in clusters (2-3) in and around aspen groves. Adult forms of the species can be found in both areas from May to June.

Morchella semilibera (Half-free Morel: Fig. $2 \mathrm{i}, \mathrm{j}$ ). The cap of the fruiting body is bluntly conical to round or oval when young, usually conical when aged. The cap is $14-18 \mathrm{~mm}$ long and 25-28 mm wide. Margin of the cap is distinctly free from the stalk or stipe (unlike other species), often flared outward. Pits may be large and elongated when mature. Ridges are usually vertically oriented. Colour of the cap may vary from yellowish brown to brown or grayish brown. Colour of pits vary from yellowish brown to brown. The stalk is hollow and it measures $25-60$ $\mathrm{mm}$ long and 10-20 mm thick. This species occurs scattered singly or in small clusters of two to five individuals in aspen woods or in moist sandy loam. It is found in both the Cypress Hills and around Strawberry Lakes.

Edibility Like some mushrooms, the morels are edible but arguably more delicious and nutritious. Most of the fresh weight of the morels, like the mushrooms, is water (about $80-90 \%$ ) and the remaining mostly proteins and amino acids, minerals and small amounts of carbohydrates. ${ }^{2,6}$ The morels are considered prized delicacies, as much as truffles, but unlike the common mushrooms their availability is seasonal. They occur in relatively greater abundance only early in spring (April-May). The morels are much tastier and better flavoured than the more extensively cultivated button mushroom (Agaricus). Unfortunately, the efforts to cultivate morels commercially have so far been in vain. ${ }^{3}$ The morels in the wild are known to develop and mature or age more slowly than many mushrooms and they are known to last for a period of up to three to four weeks. $^{2}$ However, in many parts of southern Saskatchewan, especially in the eastern Cypress Hills and around the Strawberry Lakes, the presently reported species last for two to three weeks. They can be collected early in spring (April-May) or rarely in June. Often, since the stalk or stipe is hollow, the morel fungus may harbour some unwanted worms, slugs or other small organisms or dirt and sand. They can be cleaned, hung on a string for sun-drying, and then stored in airtight jars. ${ }^{2}$ They can also be dried under a warm light bulb. Freezing is also a good way to preserve morels. However, they may decompose soon after they thaw out. To avoid this, they can be cleaned and sauteed before freezing.

Eating raw morels, most of which are reported to be not poisonous, is known to cause some digestive discomfort, especially when taken in large amounts. ${ }^{2}$ It is always advisable to wash and cook them before eating. Morels can be sauteed or served on toast or in soup. As the stipe is hollow, the morels can be split lengthwise and stuffed with cheese, rice, etc. (larger specimens are preferred for stuffing). The mo- 
rels, fresh or dry, can also be spiced, pan-fried and served on toast or rice. All four species described herein are good to eat, $M$. esculenta being excellent.

1. ALEXOPOULOS, C.J. and C.W. MISS. 1979. Introductory mycology. Red edition. John Wiley and Sons, New York.

2. ARORA, D. 1986. Mushrooms demystified. Ten Speed Press, Berkeley, California, USA.

3. GRAY, W.D. 1973. The use of fungi as food and in food processing, Part II. CRC Press, The Chemical Rubber Company, Cleveland, Ohio, USA.
4. KENDRICK, B. 1992. The fifth kingdom. 2nd ed. Focus Information Corporation Incorporated, Newburyport, Massachusetts, USA.

5. PACIONI, G. 1981. Guide to mushrooms. Simon and Schuster, New York.

6. PATHAK, N.C. 1986. Utilization of natural mushrooms flora. Pp. 43-57, in Beneficial fungi and their utilization (M.C. Nair and S. Balakrishnan, eds.). Scientific Publishers, Jodhpur, India.

7. PRATT, C.B. 1967. Are you interested in mushrooms? Blue Jay 25:8182.

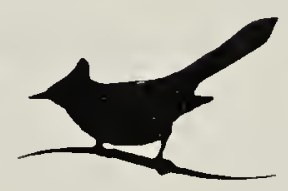

Finally, the question of central interest is how much of the world's biodiversity we can expect to carry with us out of the bottleneck fifty or a hundred years hence. Let me venture a guess. If the biodiversity crisis remains largely ignored and natural habitats continue to decline, we will lose at least one quarter of the earth's species. If we respond with the knowledge and technology already possessed, we may hold the loss to 10 percent. At first glance the difference may seem bearable. It is not; it amounts to millions of species.

Humanity coevolved with the rest of life on this particular planet; other worlds are not in our genes. Because scientists have yet to put names on most kinds of organisms, and because they entertain only a vague idea of how ecosystems work, it is reckless to suppose that biodiversity can be diminished indefinitely without threatening humanity itself. Field studies show that as biodiversity is reduced, so is the quality of the services provided by ecosystems. Records of stressed ecosystems also demonstrate that the descent can be unpredictably abrupt. As extinction spreads, some of the lost forms prove to be keystone species, whose disappearance brings down other species and triggers a ripple effect through the demographies of the survivors. The loss of a keystone species is like a drill accidentally striking a powerline. It causes lights to go out all over. E.O. Wilson, 1992. The diversity of life. W.W. Norton and Company, New York. 424 pp. 